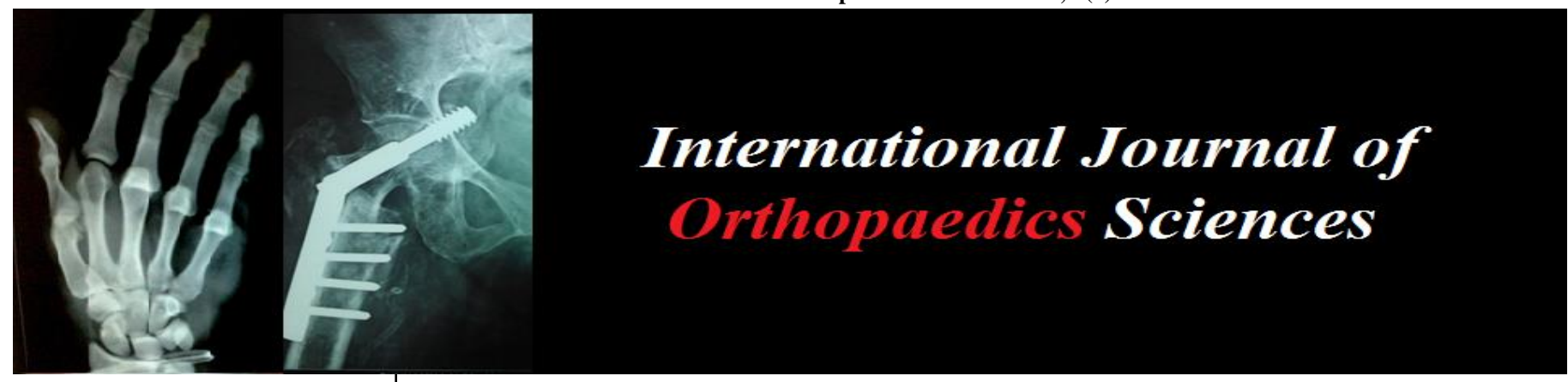

ISSN: $2395-1958$

IJOS 2018; 4(4): 579-585

(C) 2018 IJOS

www.orthopaper.com

Received: 09-08-2018

Accepted: 13-09-2018

Dr. Sandeep Ingle

Senior resident, Orthopaedics,

SVNGMC, Yavatmal,

Maharashtra, India

Dr. Sanjay Bharti

Associate Professor,

Orthopaedics, SVNGMC

Yavatmal, Maharashtra, India
Correspondence

Dr. Sanjay Bharti

Associate Professor,

Orthopaedics, SVNGMC

Yavatmal, Maharashtra, India

\section{A Comparative study to evaluate the effectiveness of lumbar epidural local anaesthetic injection with or without corticosteroid in managing chronic low back pain}

\author{
Dr. Sandeep Ingle and Dr. Sanjay Bharti
}

DOI: https://doi.org/10.22271/ortho.2018.v4.i4g.64

\section{Abstract}

The aim was to compare and evaluate the effectiveness of lumbar epidural local anaesthetic injections with and without corticosteroids in managing low back pain. We studied a 100 patients to assess effectiveness of epidural injections with local anaesthetics (bupivacaine $0.25 \%$ ) with or without steroids with regards to subjective outcomes as per pain relief by using VAS (visual analogue scale) and McGill Pain Questionnaire and objective outcomes (assessed by Straight Leg Raising test [SLR]) at the same time points - baseline prior to treatment, 3 hours after epidural injection, at 6 weeks, at 3 months. The adverse effects or complications of epidural injection, if any were noted. We concluded that the inclusion of steroids did not provide any additional benefit compared with injection of local anesthetic alone. However epidural steroid should be considered before surgical intervention. After early adequate pain control, rehabilitation can be effective and function can be restored.

Keywords: epidural local anaesthetic injections with or without corticosteroids, lower back pain

\section{Introduction}

Back pain and related symptoms rank among the second most frequent medical complaints. Disability from low back pain is second only to the common cold as a cause of lost work time and is the most common cause of disability in people under 45 years of age ${ }^{[1]}$.

Chronic back pain represents an important health problem in orthopedic practice. The number of patients presenting with low back pain constitute nearly $80 \%$ of OPD practice. Most of the patients presenting to us are of rural background involved in heavy physical labour. Low back pain temporarily disables them in earning a livelihood. So an approach has to be worked out to alleviate their symptoms early. Multiplicity of causes and difficulties in its treatment render low back ache as one of the most frequent conditions that an orthopedic surgeon encounters. Decisions regarding optimal management are not easy. There are many therapeutic interventions available; however, none seems to be clearly superior. At one end of the spectrum is the regime of bed rest and analgesics, forming the main pillar of the treatment while at the other, there is the operative removal of the prolapsed disc and other stabilization procedures. Even in the conservative line of treatment, there is no universally accepted policy and the best form of treatment. This wide and haphazard spectrum of treatment suggests that there is no single satisfactory method of treatment that ensures permanent and long lasting cure [2].

Radicular pain defined as pain that radiates from the site of a pinched nerve in the low back to the area of the body aligned with that nerve, such as the back of the leg or into the foot ${ }^{[3]}$. An important cause of radicular pain is mechanical compression exerted by degenerative changes in the facet joint, the posterior longitudinal ligament or the herniated disc. As a result, they contribute to pain mechanisms by triggering venous congestion and/or neural edema around the nerve root, for this reason, the local delivery of steroids seems to be a rational option ${ }^{[4]}$. Epidural injections for managing chronic pain are one of the most commonly performed interventions. However, controversy continues regarding the effectiveness of epidural steroid 
injections. They have been used to treat radicular pain from herniated discs, spinal stenosis, Chemical discs and axial spinal pain. The evidence is highly variable based on the reviewer and the evidence has been rated from indeterminate to strong in various publications. In addition, 3 types of epidurals, namely interlinear, transformational and caudal; and administration in 3 separate regions namely lumbar, cervical and thoracic, with variable results complicate the picture of practice of interventional pain management. Spinal pain is the most common of all chronic pain disorders. The lifetime prevalence of spinal pain has been reported as $54 \%$ to $80 \%$. Annual prevalence of chronic low back pain ranges from $15 \%$ to $45 \%$. Studies of the prevalence of low back pain and neck pain and impact on general health showed $25 \%$ of patients reporting Grade II to Grade IV low back pain (high pain intensity with disability), whereas it was $14 \%$ in patients with neck pain. There are not any interventions which provide definite and long-term improvement in chronic low back pain, neither conservative nor surgical ${ }^{[5]}$ Further, postlaminectomy syndrome and other symptoms, such as post-surgery syndrome, representing a cluster of syndromes wherein the expectations of the patient and the spine surgeon are not met.

The clinical diagnosis of low back pain \& sciatica (Stevens J, 1968) covers a large number of different disorders, the commonest being prolapsed intervertebral disc (90\%), then soft tissue disorders, such as lumbo-sacral strain, fibrositis, myosititis, osteoarthritis, \& miscellaneous, in that order of frequency. Other, although rare, conditions that are equally important, needs to be ruled out e.g. specific infections such as pyogenic osteomyelitis, tuberculous spondylitis \& brucellosis, \& non-specific conditions, such as ankylosing spondylosis, rheumatoid arthritis, osteomalacia, paget's disease etc., neoplastic such as myelomatosis, neurofibromatosis, hemangiomas, lipomas, \& primary or secondary malignant tumors of the spine and metabolic disorders such as severe osteoporosis ${ }^{[6]}$.

Symptoms in degenerative lumbar spinal stenosis are caused by a combination of central, lateral recess, and intervertebral foraminal stenosis that occurs as a part of a degenerative cascade. Neurogenic claudication is the hallmark for symptomatic LSS. Classically described as lower limb or buttock pain brought on by prolonged standing or walking, the pain distribution may be unilateral or bilateral, monoradicular or polyradicular, and may include a component of paresthesias and weakness. Low back pain is common but is not always present. Activities involving lumbar extension such as prolonged overhead reaching or walking downhill are typical exacerbating factors. Lumbar flexion postures, such as bending forward, pushing a shopping cart, or sitting down typically relieves symptoms. Patients may complain of walking with a stooped-forward posture.

Nevertheless, the benefit and most effective route of administration for epidural steroids remains controversial. The underlying mechanism of action of epidurally administered steroid and local anesthetic injections is still not well understood. It is believed that the achieved neural blockade alters or interrupts nociceptive input, reflex mechanisms of the afferent fibers, self-sustaining activity of the neurons, and the pattern of central neuronal activities. Further, it is believed that local anesthetics interrupts the painspasm cycle and reverberating nociceptor transmission. On the other hand, corticosteroids reduce inflammation by inhibiting either the synthesis or release of a number of proinflammatory mediators and by causing a reversible local anesthetic effect.
The purpose of this study was to evaluate the effectiveness of epidural injection in the management of various types of chronic back pain (axial and radicular, cervical and lumbar). We included patients who received injection (bupivacaine $0.25 \%$ (a local anaesthetic drug) with or without steroids (methylprednisolone) based on clinical decision. Patient outcomes were assessed for effectiveness of this procedure with regard to subjective outcomes (assessed by Visual Analogue Scale [VAS] for pain and McGill pain Questionnaire) and objective outcomes (assessed by Straight Leg Raising test [SLR]) evaluated at baseline prior to treatment, 3 hours and 6weeks for short term outcomes and at 3 months for long term outcomes following epidural injections.

Epidural injections is main treatment in chronic low back pain patients. Previously some studies showed that epidural steroids are more effective than epidural local anaesthetics. But other studies showed there is not much difference between these two groups, still most of the orthopeditians prefer epidural injections with steroid [7]. Hence our study tried to compare the results of epidural local anaesthetics with steroid and without steroids.

\subsection{The Epidural Space}

The epidural space is a potential, elliptical, or annular space between the spinal dura \& the bony vertebral canal.

Contents: Contents of the epidural space include the dural sac spinal nerve roots, the extradural plexus of veins, spinal arteries, lymphatics and fatty tissue.

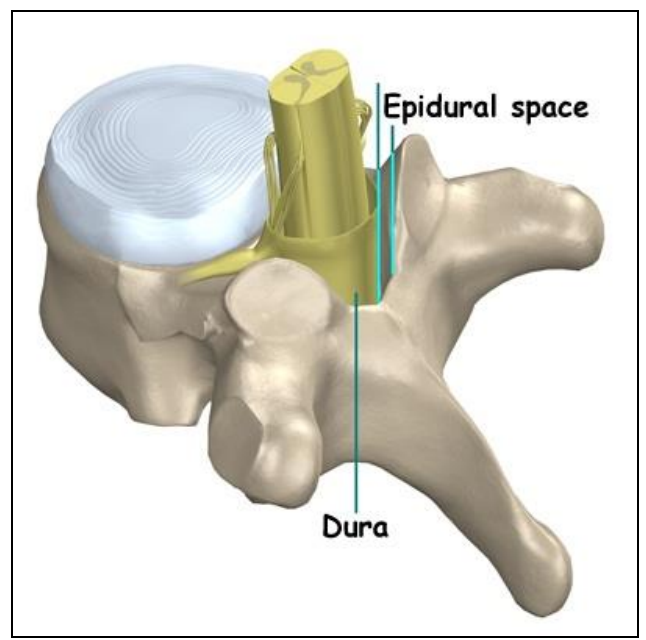

Fig 11: Epidural space

\subsection{Treatment}

From the onset it must be emphasised that there is no a single treatment for backache \& sciatica offering a complete \& permanent cure. The three most effective components are:

a. Exercise \& heat to lumbar spine

b. Manipulation \& traction

c. Epidural injection

Broadly speaking total management of backache falls into three groups:

\subsubsection{Conservative Treatment}

This, in almost all the cases suffering from disc syndrome, forms the first line of treatment. Various moidalities are:

Oral drugs- Nonnarcotic analgesics, Acetaminophen, Aspirin, Nonsteroidal anti-inflammatory agents, Muscle relaxants, Antidepressants, Corticosteroids etc. 
Physical measures: Bed rest, Activity modification, Exercise, Manipulation, Local heat, Superficial (hot packs), Deep (ultrasound or diathermy), Local cold, Massage, mobilization, and other soft-tissue techniques.

Injection drugs: Anesthetics (epidural and facet joint), Corticosteroids (epidural and facet joint)

Stimulation: Acupuncture, Transcutaneous electrical nerve stimulation (TENS), implanted neurostimulators

There appears to be general agreement in that all forms of conservative treatment are effective $\&$ beneficial to the patient in some form or other. The choice \& plan of conservative treatment is very much a better of the clinician's own likings and dislikings and is indeed his ideas, interests and beliefs ${ }^{[8]}$.

\subsubsection{Surgical Treatment}

This involves removal of the extruded disc either through fenestration surgery or wide laminectomy, which may or may not be followed by arthrodesis of the spine. Operative removal of the prolapsed disc tissue for the relief of persistent sciatica is now accepted as a valuable \& safe procedure, attended with very good prospect of cure \& minimal morbidity. A more realistic \& aggressive attitude is more desirable \& beneficial for the patient once conservative treatment has failed to relieve the symptoms.

\subsubsection{Prophylactic Treatment}

The main role of prophylaxis comes after the completion of conservative $\&$ operative treatment $\&$ is aimed at prevention of recurrence of symptoms. Prophylaxis consists of the correction of both the dynamic \& static posture \& to avoid undue \& unnecessary stresses \& strains which predispose the herniation of the disc.

\section{Materials and Methods}

Study design: Prospective, non-Randomized Clinical Trial

Study period: January 2018 to August 2018.

Study population: Patients with chronic back pain who had given consent for epidural injection and had attained skeletal maturity.

\section{Study inclusion criteria}

1. Both genders

2. Over 20 years old with skeletal maturity and given consent to participate.

3. Chronic back pain for a minimum period of 6 months.

4. Patients who had taken conservative treatment before like medications, yoga or physiotherapy.

5. Patients with comorbidities including hypertension, Diabetes Mellitus.

\section{Study exclusion criteria}

1. Acute back pain (less than 6 months duration)

2. Age less than 20 years

3. Any vertebral fractures due to accidents

4. Patients who have previously received epidural injection

\subsection{Methodology}

After selecting the cases on the basis of the above mentioned criteria, they were counselled about the study \& were included after a written informed consent to participate in the study. All the patients underwent a thorough clinical evaluation in way of a history of the illness, including the details of pain, as well as the nature of the conservative treatment they had received in the past, examination including neurological assessment of the lower limb as per a proforma prepared for the study. They were subjected to questionnaires including the Visual Analogue Scale, McGill Pain Questionnaire were evaluated before \& after the intervention and at follow up. The investigations that were done for every patient included an X-ray Lumbo-Sacral Spine - AP and LAT,MRI Lumbosacral Spine, Routine Hemogram, HIV and HBsAg status, Bleeding and Clotting time. Assignment of patients to the study intervention according to study flow chart into two groups

Group 1: Those patients who had given epidural local anaesthetics with steroid

Group 2: Those patients who had given epidural local anaesthetics only

\subsection{Study Interventional Procedure Epidural injection method}

\section{Preparation \& Position of the Patient:}

The procedure was carefully explained to the patient and told to expect increase in intensity of his symptoms during the injection. All the injections were carried out in the operation theatre with dry, sterile materials. Neurological Status \& SLRT were re-assessed at this stage. With the patient in sitting or lateral decubitus posture (affected side down in those who could not sit), lumbo sacral region was prepared with spirit \& povidine iodine several segments above \& below the laminar interspace to be injected. Sitting position was preferred as the fully flexed spine lead to opening of the interspinous spaces which were being used for the injection.

\subsubsection{Procedure}

After positioning the patient \& preparation of the skin, the target laminar interspace was identified. Commonly used anatomical landmarks were the highest point of the iliac crest, with L- 4 spinous process. Using a needle, the skin over the target interspace was injected with 1 to $2 \mathrm{ml}$ of $2 \%$ preservative-free Xylocaine without epinephrine \& was anaesthetized. The target space was within one level above or below the level of symptomatic disc. Then a 31/2-inch, 18gauge Tuohy epidural needle was inserted \& advanced it vertically within the anesthetized soft tissue track until contact with the lamina has been made. "Walk off" the lamina with the Tuohy needle onto the ligamentum flavum was done. Stylet from the Tuohy needle was removed \& attached to a $10-\mathrm{ml}$ syringe filled with air. It was advanced into the epidural space using the loss of resistance technique. This was followed by securing the needle \& then injecting $4 \mathrm{ml} 0.25 \%$ Bupivacaine and $2 \mathrm{ml}$ of $80 \mathrm{mg} / \mathrm{ml}$ Methyl Prednisolone Acetate(Depomedrol) one after the other, a total of $6 \mathrm{ml}$. Finally the tuohy needle was withdrawn $\&$ the spot was sealed with tincture benzoin. All the procedures were done by a anaesthetist.

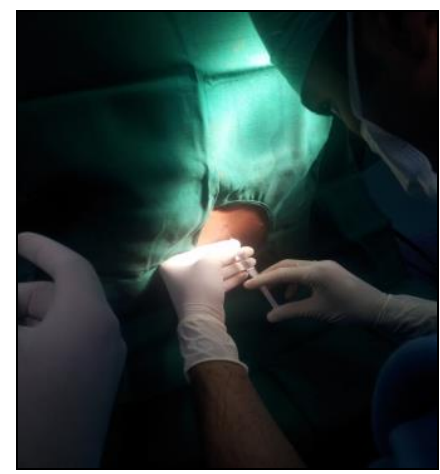

Fig: showing local infiltration 


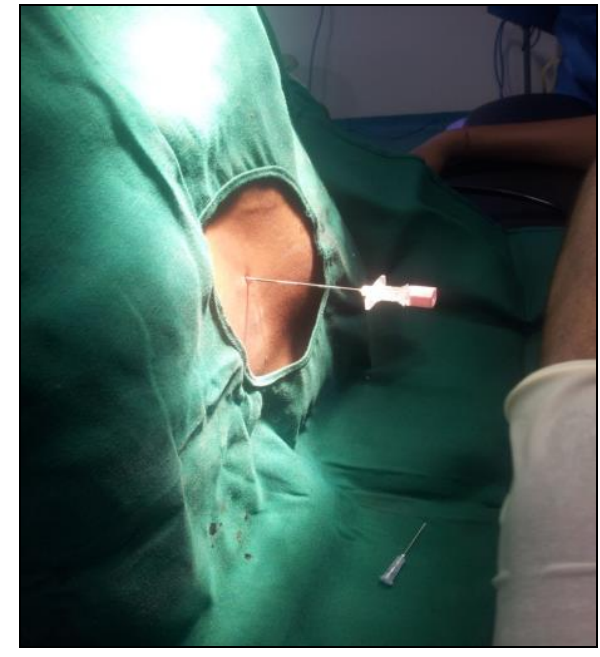

Fig: showing Epidural needle in situ

At the conclusion of the injection a note was made of the following: relief of pain $\&$ its extent measured subjectively as well as by straight leg raising test, motor and sensory examination. The patient was advised that apart from a feeling of warmth in the legs \& perhaps a sensation of walking on cotton wool, there should be no other neurological signs or untoward effect. The patient was further warned that after injection the pain may be worsened for a few days before it begins to settle. The patient was advised to lie flat for at least $45 \mathrm{~min}$ after the injection which helped to avoid headache developing on sitting up. The patient was advised to pass urine before leaving the hospital. Back extension exercises were continued after the injection as a routine protocol.

Clinical evaluations were performed immediately after the injection, at 6 weeks \& 3 months. The Visual Analogue Score, Mc Gill Pain Questainnaire were used to differentiate patients whose symptoms improved from those who remained symptomatic. Patient satisfaction was documented at 3 months.Excellent-100\% reduction of symptoms/disability, Good- $>50 \%$ reduction, Fair- $<50 \%$ reduction Poor-same or worse.

\subsubsection{Post procedure monitoring}

Immediate after the procedure around after 3 hours outcome was measured by Visual Analogue Scale and by McGILL Pain Questionnaire.

\subsubsection{Follow up}

Was done_as short term outcome at 6 weeks and long term outcome at around 3 months. At each visit patients were detailed examined by VAS, McGILL Questionnaire.

\subsection{Study analysis and statistical methods}

All data was collected and entered in master chart / spreadsheet - Descriptive statistics of the study patients was provided, including the demography (age, gender, and comorbidies) and clinical details of chronic low back pain. Study outcomes, both subjective and objective were compared between patients receiving epidural local anaesthetic alone and those getting local anaesthetic along with steroids at the time points mentioned i.e. Baseline (prior to treatment), 3 hours, 6 weeks and 3 months post epidural injection. Continuous variables (means VAS pain scale) were compared between groups using unpaired t test; categorical variables were compared by using chi square test. $\mathrm{P}$ value $<0.05$ was considered significant for this study.

\section{Study definitions}

1. Chronic low back pain: Is defined as a patient is having low back pain with or without radiculitis for minimum period of 6 months.

2. VAS (Visual Analogue Scale) - The pain VAS is a unidimensional measure of pain intensity, which has been widely used in diverse adult population. The pain VAS is a continuous scale comprised of a horizontal (HVAS) or vertical (VVAS) line, usually 10 centimeters $(100 \mathrm{~mm})$ in length. The pain VAS is a single-item scale. Response options/scale. For pain intensity, the scale is most commonly anchored by "no pain" (score of 0 ) and "pain as bad as it could be" or "worst imaginable pain" (score of 100 [100-mm scale])

\section{Bservations and results}

Table 1: Age distribution of patients

\begin{tabular}{|c|c|c|c|}
\hline Age & Group 1 & Group 2 & Total \\
\hline $20-30$ & $10(14.29 \%)$ & $9(30.00 \%)$ & $19 \%$ \\
\hline $30-40$ & $16(22.86 \%)$ & $7(22.33 \%)$ & $23 \%$ \\
\hline $40-50$ & $23(32.86 \%)$ & $6(20.00 \%)$ & $29 \%$ \\
\hline Above 50 & $21(30.00 \%)$ & $8(26.67 \%)$ & $29 \%$ \\
\hline Total & 70 & 30 & 100 \\
\hline
\end{tabular}

Table 2

\begin{tabular}{|c|c|c|c|}
\hline \multicolumn{2}{|c|}{ Sex distribution of patients } & & \\
\hline Sex & Group 1 & Group 2 & Total \\
\hline Male & $32(45.71 \%)$ & $19(63.33 \%)$ & $51 \%$ \\
\hline Female & $38(54.29 \%)$ & $11(36.67 \%)$ & $49 \%$ \\
\hline Total & 70 & 30 & 100 \\
\hline
\end{tabular}

It was observed that majority of the patients $55 \%$ in group 1 and $43 \%$ in group 2 were in age group between $30-50$ years. $30 \%$ in group 1 and $27 \%$ in group 2 were above the age of 50 years. It was observed that majority of patients were females $(54 \%)$ in group 1 and males $(63 \%)$ in group 2.

Table 3: Distribution of patients according to McGill Pain Questionnaire before treatment

\begin{tabular}{|c|c|c|c|}
\hline $\begin{array}{c}\text { McGill Questionnaire } \\
\text { before treatment }\end{array}$ & Group 1 & Group 2 & Total \\
\hline $0-20$ & $5(7.14 \%)$ & $1(3.33 \%)$ & $6 \%$ \\
\hline $21-40$ & $21(30 \%)$ & $6(20 \%)$ & $27 \%$ \\
\hline $41-60$ & $31(44.29 \%)$ & $15(50 \%)$ & $46 \%$ \\
\hline 61 \& Above & $13(18.57)$ & $8(26.67 \%)$ & $21 \%$ \\
\hline Total & 70 & 30 & 100 \\
\hline
\end{tabular}

It was observed that most of the patients had McGill Pain Questionnaire score between 41-60 in both groups

Table 4: In this table majority of the patients had VAS Score $>5$ in both groups distribution of patients according to VAS score before treatment

\begin{tabular}{|c|c|c|c|}
\hline VAS Score before treatment & Group 1 & Group 2 & Total \\
\hline$<=5$ & $20(28.57 \%)$ & $5(16.67 \%)$ & $25 \%$ \\
\hline$>5$ & $50(71.43 \%)$ & $25(83.33 \%)$ & $75 \%$ \\
\hline Total & 70 & 30 & 100 \\
\hline
\end{tabular}

Table 5: Comparison Means of McGill Pain Score Questionnaire

\begin{tabular}{|c|c|c|c|c|c|}
\hline \multirow{2}{*}{$\begin{array}{c}\text { ill Pain } \\
\text { Questainnaire }\end{array}$} & \multicolumn{2}{|c|}{ Group 1 } & \multicolumn{2}{|c|}{ Group 2 } & \multirow{2}{*}{ Mean } \\
\cline { 2 - 6 } & $\begin{array}{c}\text { Std. } \\
\text { Deviation }\end{array}$ & Mean & $\begin{array}{c}\text { Std. } \\
\text { Deviation }\end{array}$ & P Value \\
\hline before treatment & 46.14 & 1.81 & 49.87 & 2.59 & 0.243 \\
\hline after 6 weeks & 19.87 & 1.19 & 26.2 & 2.3 & 0.019 \\
\hline after 3 months & 20.23 & 1.14 & 27.2 & 2.3 & 0.009 \\
\hline
\end{tabular}


Table 6: Paired t test showing mean difference of McGill Pain score before and after treatment in group1

\begin{tabular}{|c|c|c|c|c|}
\hline McGill Pain Questainnaire & Mean difference & Std. Deviation & T & p value \\
\hline (before treatment) - (after 6 weeks) & 26.27 & 11.84 & 18.56 & $<0.001$ \\
\hline (before treatment) - (after 3 months) & 25.91 & 12.79 & 19.95 & $<0.001$ \\
\hline (after 6 weeks) - (after 3 months) & -0.36 & 3.54 & -0.84 & 0.402 \\
\hline
\end{tabular}

It was found that there was significant positive correlation between before and after treatment while insignificant correlation between short term and long term outcome. $\mathrm{P}$ value was highly significant.

Table 7: Paired t test showing mean difference of McGill Pain score before and after treatment in group 2

\begin{tabular}{|c|c|c|c|c|}
\hline McGill Pain Questionnaire & Mean difference & Std. Deviation & T value & p value \\
\hline (before treatment) - (after 6 weeks) & 23.67 & 13.07 & 9.92 & $<0.001$ \\
\hline (before treatment) - (after 3 months) & 22.67 & 11.72 & 10.59 & $<0.001$ \\
\hline (after 6 weeks) - (after 3 months) & -1 & 3.05 & -1.79 & 0.083 \\
\hline
\end{tabular}

There was a significant positive correlation before and after treatment while insignificant correlation between short term and long term outcome. $\mathrm{P}$ value highly significant.

Table 8: Comparison of VAS Score

\begin{tabular}{|c|c|c|c|c|c|}
\hline \multirow{2}{*}{ VAS score } & \multicolumn{2}{|c|}{ Group 1 } & Group 2 & \multirow{2}{*}{ P Value } \\
\cline { 2 - 5 } & Mean & Std. Deviation & Mean & Std. Deviation & \\
\hline VAS (before treatment) & 6.01 & 0.19 & 6.53 & 0.26 & 0.108 \\
\hline VAS (after 6 weeks) & 1.51 & 0.23 & 2.93 & 0.38 & 0.002 \\
\hline VAS (after 3 months) & 2.12 & 0.25 & 3.27 & 0.4 & 0.019 \\
\hline
\end{tabular}

It was found that mean score of VAS was reduced after treatment in both groups. P value was insignificant.

Table 9: Paired $t$ test showing mean difference of VAS score before and after treatment in with steroid group.

\begin{tabular}{|c|c|c|c|c|}
\hline VAS score & Mean difference & Std. deviation & t value & P \\
\hline VAS (before treatment) - VAS (after 6 weeks) & 4.5 & 2.21 & 17.02 & $<0.001$ \\
\hline VAS (before treatment) - VAS (after 3 months) & 3.87 & 2.27 & 14.04 & $<0.001$ \\
\hline VAS (after 6 weeks) \& VAS (after 3 months) & -0.59 & 1.15 & -4.22 & $<0.001$ \\
\hline
\end{tabular}

This study shows mean difference of VAS was highly significant between before and after treatment group. Also it showed negative mean difference between short term and long term outcome group. P value highly significant.

Table 10: Paired $t$ test showing mean difference of VAS score before and after treatment in without steroid group

\begin{tabular}{|c|c|c|c|c|}
\hline VAS score & Mean difference & Std. deviation & t value & P \\
\hline VAS (before treatment) - VAS (after 6 weeks) & 3.6 & 1.99 & 9.89 & $<0.001$ \\
\hline VAS (before treatment) - VAS (after 3 months) & 3.27 & 2.12 & 8.46 & $<0.001$ \\
\hline VAS (after 6 weeks) \& VAS (after 3 months) & -0.33 & 0.88 & -2.07 & 0.048 \\
\hline
\end{tabular}

This study showed mean difference of VAS was highly significant between before and after treatment group. It showed negative mean difference between short term and long term outcome group. P value highly significant.

Table 11: Association of McGill score before $t / t$ with patient satisfaction.

\begin{tabular}{|c|c|c|c|}
\hline McGill Score & Before treatment & At 6 weeks & At 3 months \\
\hline $0-20$ & 6 & 58 & 58 \\
\hline $20-40$ & 27 & 31 & 32 \\
\hline $40-60$ & 46 & 11 & 10 \\
\hline$>60$ & 21 & 0 & 0 \\
\hline Total & 100 & 100 & 100 \\
\hline
\end{tabular}

\begin{tabular}{|c|c|c|c|c|c|c|}
\hline \multicolumn{7}{|c|}{ Association of McGill Pain score after 6 weeks with Patient satisfaction } \\
\hline \multirow{2}{*}{ McGill Score after 6 weeks } & \multicolumn{4}{|c|}{ Patient satisfaction } & \multirow{2}{*}{ Total } & \multirow{2}{*}{$\mathbf{X} 2, \mathbf{p}$} \\
\hline & Excellent & Good & Fair & Poor & & \\
\hline $0-40$ & 20 & 38 & 26 & 5 & 89 & \multirow{3}{*}{$0.54,0.91$} \\
\hline 41\& Above & 2 & 4 & 4 & 1 & 11 & \\
\hline Total & 22 & 42 & 30 & 6 & 100 & \\
\hline \multicolumn{7}{|c|}{ Association of McGill Pain score after 3 months with Patient satisfaction } \\
\hline \multirow{2}{*}{ McGill Score after 3 months } & \multicolumn{4}{|c|}{ Patient satisfaction } & \multirow{2}{*}{ Total } & \multirow{2}{*}{$\mathbf{X} 2, \mathbf{p}$} \\
\hline & Excellent & Good & Fair & Poor & & \\
\hline $0-40$ & 20 & 39 & 26 & 5 & 90 & \multirow{3}{*}{$1.07,0.79$} \\
\hline 41\& Above & 2 & 3 & 4 & 1 & 10 & \\
\hline Total & 22 & 42 & 30 & 6 & 100 & \\
\hline
\end{tabular}


A total of hundred patients were evaluated for a period of minimum 3 months post epidural injection with or without steroid, in terms of effectiveness. All the patients were divided into two groups, group 1 includes patients who were taken epidural injection with steroid and group 2 includes patients who were taken epidural injection without steroid. The mean age of group 1 was 44.79 and $55 \%$ were in the middle age group between 30 to 50 years, while mean age group of group 2 was 40.6 and $44 \%$ were in middle age group. $55 \%$ patients were females and $45 \%$ were males in group 1 while in group $263 \%$ were males and $37 \%$ were females and overall patients in our study were $51 \%$ males and $49 \%$ females.

The majority i.e. $55 \%$ of patients in goup 1 and $70 \%$ of patients in group 2 had symptoms $<12$ months.

It was observed that $63 \%$ patients of group 1 and $60 \%$ patients of group 2 were previously treated by rest and analgesics, while $37 \%$ of group 1 and $40 \%$ of group 2 were treated by physiotherapy. Overall $15 \%$ patients had diabetes mellitus and $15 \%$ patients had hypertension.

Complications in this study included $6 \%$ headache, $7 \%$ had pain at injection site and $2 \%$ had dural puncture. It was observed that $44 \%$ patients of group 1 and $50 \%$ of patients in group 2 had McGill Pain Questionnaire Score between 41-60. It was also observed that $72 \%$ patients of group 1 and $84 \%$ patients of group 2 had VAS $>5$.

In this study it was found that mean score of VAS was 6.01 before treatment in group1 which improved to 1.51 at 6 weeks post treatment and 2.12 at 3 months post treatment. Mean score of VAS in group 2 was 6.53 before treatment which improved to 2.93 at 6 weeks post treatment and 3.27 at 3 months post treatment. Paired t test showed mean difference 4.5 between before treatment and 6 weeks after treatment and mean difference 3.87 between before treatment and 3 months after treatment in group 1. It showed mean difference 3.6 between before treatment and 6weeks after treatment and mean difference 3.27 between before treatment and at 3 months after treatment in group2. $\mathrm{P}$ value was highly significant in both groups.

\section{Discussion}

Low backache due to lumbar nerve root compromise is a debilitating problem frequently afflicting otherwise healthy individuals. Pain and reduced mobility severely compromise their quality of life. The aim of any therapy should be to return to a normal lifestyle as soon as possible, whether it be by treatment of the underlying cause or merely by symptomatic relief. It is recommended that surgery to be undertaken only when conservative management fails.

Etiology of low backache remains controversial. Degeneration, herniation, or by an inflammatory reaction could be responsible for lower backache \& sciatica. An epidural injection can decrease inflammation in the epidural space as well as the pain in the affected nerve root.

It is challenging to treat the disabling pain associated with chronic low back ache, with or without surgery. A previous report, showed surgery to be more effective than conservative management. However, no studies with the criteria of contemporary interventional pain management have been conducted to assess the conservative management approach used in the past. Consequently, the most effective management strategy for chronic low back ache has not been still determined, even though the condition was first reported in 1954, when it was characterized by the narrowing of spinal canal, neurogenic spinal claudication, and radicular pain.
Reports indicate that only a subgroup of patients has a good response to surgical intervention for spinal stenosis, whereas other subgroups of patients respond well to epidural injections. However, until now no studies could explicitly delineate the characteristics of these subgroups. Future studies should focus on these issues.

In this study, a total of hundred patients were evaluated for a period of minimum 3 months post epidural injection with or without steroid, in terms of effectiveness. All the patients were divided into two groups, group 1 included patients who were administered epidural injection with steroid and group 2 included patients who were given epidural injection without steroid.

We observed that McGill Pain Questionnaire mean score before treatment was 46.14 in group 1 which was improved to 19.18 at 6 weeks post treatment and 20.23 at 3 months post treatment. Similarly in group 2 McGill Pain Questionnaire mean score before treatment was 49.87 which was improved to 26.2 at 6 weeks and 27.2 at 3 months post treatment. When both groups compared it was found that group 1 is marginally superior to group 2 but $\mathrm{P}$ value is not significant. But there was significant improvement in both groups after treatment by McGill Pain Questionnaire score as $p$ value is highly significant. Similar observation was made by N. K. Arden et al ${ }^{[9]}$ who showed improvement from 44 to 12 at end of 3 months. These results were comparable to a study conducted by Pirbudak et al ${ }^{[10]}$ who showed significant improvement in 92 patients treated with epidural steroid.

In our study the mean score of VAS was 6.01 before treatment in group1 which improved to 1.51 at 6 weeks post treatment and 2.12 at 3 months post treatment. Mean score of VAS in group2 was 6.53 before treatment which improved to 2.93 at 6 weeks post treatment and 3.27 at 3 months post treatment. Paired t test showed mean difference 4.5 between before treatment and 6 weeks after treatment and mean difference 3.87 between before treatment and 3 months after treatment in group 1. It showed mean difference 3.6 between before treatment and 6weeks after treatment and mean difference 3.27 between before treatment and at 3 months after treatment in group2. P value was highly significant in both groups. So here VAS score was significantly improved after treatment in both groups, however there was no significant difference between two groups.

We observed that $22 \%$ of patients had excellent satisfaction, $42 \%$ of patients had Good satisfaction, $30 \%$ had fair satisfaction and only $6 \%$ had poor satisfaction after treatment. It was observed that there was no association between McGill Pain Questionnaire Score and Patient satisfaction after treatment. Manchikanti et.al. [11] showed significant pain relief and functional status improvement $(\geq 50 \%)$ were demonstrated in $48 \%$ in Group I and $46 \%$ in Group II. However, significant pain relief and functional status improvement were seen in $60 \%$ of the participants in both groups in the successful category when the participants were separated into successful and failed categories there was no difference in the functional outcome between these two groups.

There were no major complications like meningitis, allergic reactions or cauda equine syndrome. In the study it was observed that $2 \%$ of patients had Dural puncture, $7 \%$ of patients had pain at injection site and $6 \%$ had headache. These results were comparable to a study done by Michael J. DePalma [5] who showed injection site pain in $17.1 \%$, headache in $3.1 \%$.

Karppinen et.al ${ }^{[12]}$ demonstrated that either local steroid 
injection or saline injection around a nerve root would improve referred pain, but found that when a combination of steroid and local anaesthetic were used there was a rebound phenomenon after three to six months, with increasing deterioration of symptoms the longer the period between the injection and follow-up. Our patients had significant improvement by 1 month and only 3 patients underwent surgery due to poor relief. It has been shown that epidural steroid injection with local anaesthetic is better than injection of local anaesthetic alone and thus the steroid does appear to be important in reducing pain in these patients. Manchikanti $\mathrm{L}$ et al ${ }^{[11]}$ in 2012 showed that there was no significant difference between two groups one which received epidural local anaesthetics and other who received local anaesthetics with steroid.

It has been shown that significant improvement in both groups i.e. with and without steroid groups but epidural with steroid is slightly superior to without steroid group, also evidence strong for short term outcome (at 6 weeks) and limited for long term outcome (at 3 months) compared with studies Abdi. et.al ${ }^{[13]}$ showing similar results.

Many studies show that only $10 \%$ to $15 \%$ of patients presenting to a specialist eventually require operation. The reason for the low take up of surgery may have been that many of the older patients did not wish to undergo surgical treatment. A small number of patients refused to have surgery despite the failure to improve over the course of time because of the perceived risks.

This study helped us to say that epidural injection in early stage of backache helps in relief of symptoms, early return to normal daily activities and work. Epidural injection helps in patients in whom spontaneous improvement is expected by accelerating the rate of recovery. However in long term follow-up it may not preclude the need for surgery.

\section{Conclusions}

This study was done to evaluate the efficacy of epidural injections with or without steroid in low backache.

- Most of the patients with chronic low back ache were under 30-50 years age group.

- Chronic low back ache is equally distributed in males and females, there is no sex predilection.

- The results statistically showed significant improvement in terms of pain relief measured with Visual Analogue Scale score and patient satisfaction and functional return measured by McGill Pain Questionnaire Score.

- Complications encountered were injection site pain and headache.

- The inclusion of steroids did not provide any additional benefit compared with injection of local anesthetic alone. Therefore, on the basis of the current findings, there is a lack of evidence to support that the addition of steroids to epidural injections provides benefit in patients with chronic low back ache.

- Epidural steroid should be considered before surgical intervention.

- After early adequate pain control, rehabilitation can be effective and function can be restored.

\section{References}

1. Thomas von Rothenburg Robert Drescher. Odo Koester, Gebhard Schmid. Magnetic resonance imaging of the lumbar spine after epidural and nerve root injection therapy: evaluation of soft tissue changes. Clinical Imaging.
DOI: https://doi.org/10.1016/j.clinimag.2006.03.033تArt icle Info

2. Abdi S, Datta S, Lucas LF. Role of epidural steroids in the management of chronic spinal pain: a systematic review of effectiveness and complications. Pain Physician. 2005; 8(1):127-43.

3. Wilson-MacDonald J, Burt G, Griffin D, Glynn C. Epidural steroid injection for nerve root compression. A randomised, controlled trial.J Bone Joint Surg Br. 2005; 87(3):352-5.

PMID:15773645 [Indexed for MEDLINE]

4. Hee-Seung Nam, Yong Bum Park. Effects of Transformational Injection for Degenerative Lumbar Scoliosis Combined with Spinal Stenosis Ann Rehabil Med. 2011; 35(4): 514-523. doi: [10.5535/arm.2011.35.4.514]PMCID: PMC3309239PMI D: 22506167

5. DePalma MJ, Slipman CW Evidence-informed management of chronic low back pain with epidural steroid injections. Spine J. 2008; 8(1):45-55. doi: 10.1016/j.spinee.2007.09.009..PMID:18164453

DOI:10.1016/j.spinee.2007.09.009

6. Steven J 1968. J. Stevens "Low back pain" and its clinical managements. Medicla Clinics of North America 1968; 52.Thomas M, Grant N, Marshall J, Stevens J. Surgical treatment of low backache and sciatica. Lancet. 1983; 2(8365-66):1437-1439. [PubMed]

7. Manchikanti L, Cash KA, McManus CD, Damron KS, Pampati V, Falco FJ. Lumbar interlaminar epidural injections in central spinal stenosis: preliminary results of a randomized, double-blind, active control trial. Author information Pain Physician. 2012; 15(1):51-63.

8. Steven Atlas J, Richard A. Deyo Evaluating and Managing Acute Low Back Pain in the Primary Care Setting. J Gen Intern Med. 2001; 16(2):120-131. doi: [10.1111/j.1525-1497. 2001.91141.x ]PMCID: P MC1495170 PMID: 11251764

9. Arden NK, Price C, Reading I, Stubbing J, Hazelgrove J, Dunne C, et al. WEST Study Group A multicentre randomized controlled trial of epidural corticosteroid injections for sciatica: the WEST study. Rheumatology (Oxford). 2005; 44(11):1399-406. Epub.

10. Rogers P, Nash T, Schiller D, Norman J. Epidural steroids for sciatica. Pain Clinic. 1992; 5:67-72.

11. Manchikanti L, Cash KA, McManus CD, Damron KS, Pampati V, Falco FJ. Lumbar interlaminar epidural injections in central spinal stenosis: preliminary results of a randomized, double-blind, active control trial. Pain Physician. 2012; 15(1):51-63. Pain Physician.

12. Karppinen J, Malmivaara A, Kurunlahti M, Kyllönen E, Pienimäki T, Nieminen P. Periradicular infiltration for sciatica: a randomized controlled trial. Spine (Phila $\mathrm{Pa}$ 1976). 2001; 26(9):1059-67.

13. Abdi S, Datta S, Trescot AM, Schultz DM, Adlaka R, Atluri SL, Smith HS, Manchikanti L. Epidural steroids in the management of chronic spinal pain: a systematic review. Pain Physician. 2007; 10(1):185-212. 